\title{
SHORT-TERM CORROSION RESPONSE OF METALS IN LIME MORTAR
}

\author{
Pavla Bauerováa ${ }^{a, b}$, ZdenĚK ProšeK ${ }^{a, c}$, Jitka Krejsová $^{b}$, \\ MARTIN KePPERT ${ }^{a, b, *}$ \\ ${ }^{a}$ Czech Technical University in Prague, University Centre for Energy Efficient Buildings, Třinecká 1024, 27343 \\ Buštěhrad, Czech Republic \\ ${ }^{b}$ Czech Technical University in Prague, Faculty of Civil Engineering, Department of Materials Engineering and \\ Chemistry, Thákurova 7, 16629 Praha 6, Czech Republic \\ ${ }^{c}$ Czech Technical University in Prague, Faculty of Civil Engineering, Department of Structural Mechanics, \\ Thákurova 7, 16629 Praha 6, Czech Republic \\ * corresponding author: martin.keppert@fsv.cvut.cz
}

\begin{abstract}
Even though the corrosion of steel in concrete is very well described, the corrosion processes in lime environment studied very rarely. This environment is obviously also basic and its $\mathrm{pH}$ decreases in time, but the obtained results indicate important differences in behaviour of these two systems. Corrosion response of carbon steel, zinc platted steel, copper, brass and lead placed in lime mortar was studied by help of SEM microscopy.
\end{abstract}

KEYWORDS: Metal corrosion, modern mosaics, lime mortar.

\section{INTRODUCTION}

The problems related to the steel reinforcement corrosion in concrete are of crucial importance with respect to lifetime of majority of contemporary concrete structures [1. There the most important corrosion-related feature is high $\mathrm{pH}$, which, together with low potential, ensures formation of a passive layer of $\mathrm{Fe}_{3} \mathrm{O}_{4}$ or $\mathrm{Fe}_{2} \mathrm{O}_{3}$ on steel. The $\mathrm{pH}$ of concrete pore solution is controlled by soluble species present in concrete - portlandite $\left(\mathrm{Ca}(\mathrm{OH})_{2}\right)$ and eventually free alkalis $(\mathrm{NaOH}, \mathrm{KOH})$ [2]. In case that portlandite is the controlling species, the $\mathrm{pH}$ of pore solution is 12.5 , corresponding to solubility constant of portlandite; the presence of alkalis can increase $\mathrm{pH}$ to higher level (ca. 13). Obviously, also other components of pore solution are of importance towards the steel corrosion - especially chloride ions are widely studied [3].

The present paper is inspired by demand on knowledge of corrosion behavior of metallic materials in lime mortar; the demand came from restores dealing with mosaics. Modern mosaics (from $19^{\text {th }}$ and $20^{\text {th }}$ century) have been frequently created in atelier by help of a metal frame, mortar and glass or stone tesseraes, and after the hardening were installed [4]. The metal frames, as well as other mosaics' components, are frequently subjected to exterior conditions inducing complex degradation processes. The goal of the research was to evaluate corrosion behavior of carbon steel, copper, brass and lead in lime mortar environment. It is similar to the concrete environment - the pH is obviously also controlled by portlandite, but higher permeability of lime systems, responsible for their faster carbonation, makes the conditions somewhat different. Corrosion tests are commonly performed by help of an accelerated test 5 ; here just a short term response of metals to the lime environment was studied.

\section{EXPERIMENTAL}

The short-term corrosion behavior of five metals (carbon steel, copper, brass, lead) was studied. The strips $(10 \times 50 \mathrm{~mm})$ of metal plates were degreased, rinsed and immersed in fresh lime mortar (lime hydrate + standard quartz sand 1:3) and left in laboratory conditions. The used lime hydrate was compliant with CL90S type; the XRF analysis revealed that $\mathrm{CaO}$ content was $99.3 \%, \mathrm{MgO} 0.5 \%$ and $\mathrm{SO}_{3} 0.1 \%$. After three months, the metal strips were removed from the mortar, cross-cutted, fixed by epoxy resin, polished and the interface between metal and adhering mortar was examined by electron microscopy (SEM Phenom XL) in BSE mode. The mortar was not yet fully carbonated; the XRD Rietveld analysis (Fig. 1) revealed that binder (aggregates excluded) contained $38 \%$ portlandite and $62 \%$ of calcite. It means that $\mathrm{pH}$ was still controlled by $\mathrm{Ca}(\mathrm{OH})_{2}$ dissolution.

\section{Results AND DISCUSSION}

Carbon steel. The surface of carbon steel (Fig. 2) has been covered by continuous layer of $\mathrm{Fe}$ corrosion products $\mathrm{Fe}_{\mathrm{x}} \mathrm{O}_{\mathrm{y}}$; generally $\mathrm{Fe}_{2} \mathrm{O}_{3}$ and $\mathrm{Fe}_{3} \mathrm{O}_{4}$ may be formed at basic conditions, depending on the potential. The layer thickness ranged from 5 to $10 \mu \mathrm{m}$. The gap between metal and oxidized layer appeared during the sample preparation. Mortar adhered well Fe-oxides layer. The profile "1 Fe" (line scan 1) shows that Fe atoms has diffused also to the mortar layer. In areas, where mortar did not cover the steel well, a porous 


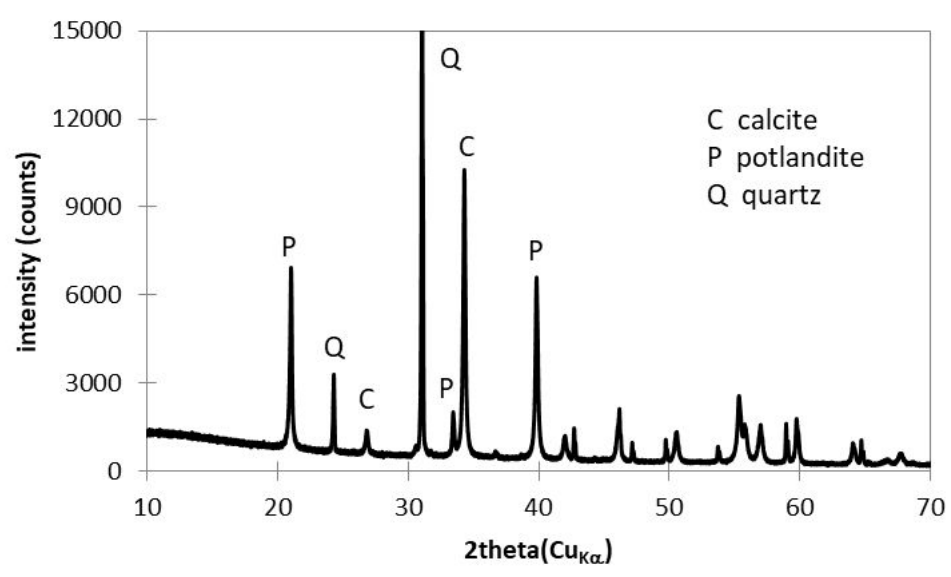

FigURE 1. Phase composition of lime mortar under study.

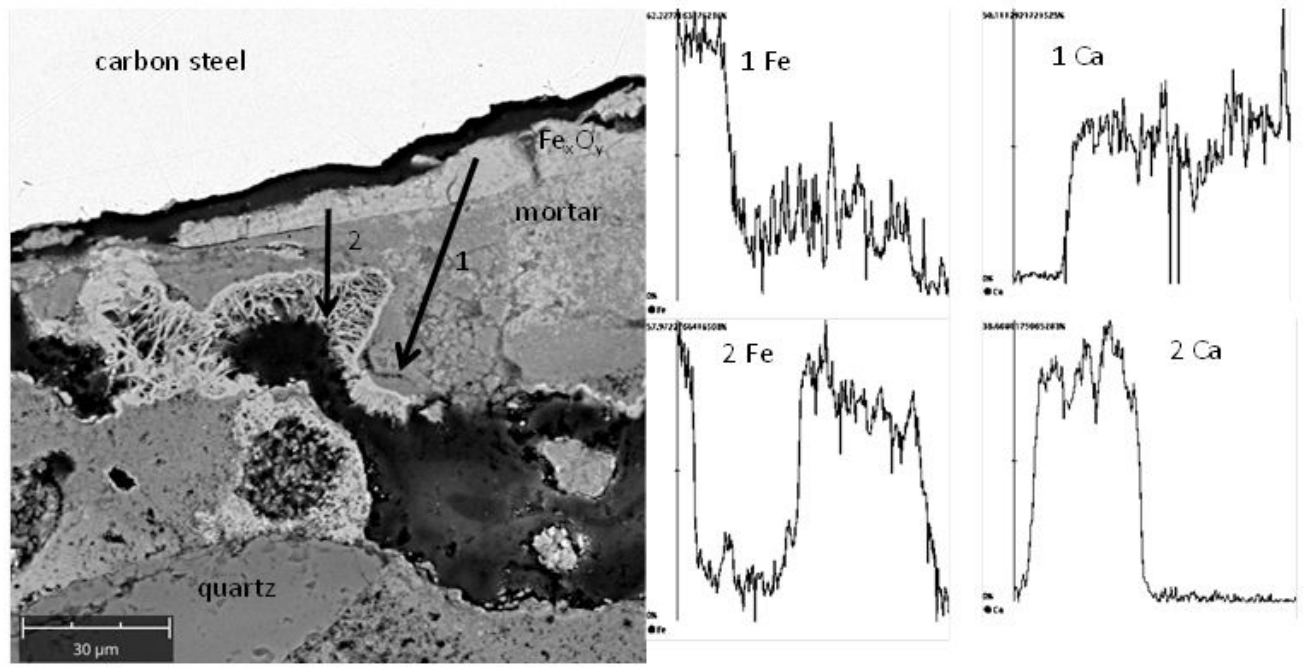

FiguRE 2. Interface between carbon steel and lime mortar. The arrows indicate line scans 1 and 2.

dendritic $\mathrm{Fe}_{\mathrm{x}} \mathrm{O}_{\mathrm{y}}$ structure appeared. The line scan 2 illustrates that the dendritic corrosion structure has grown also on the mortar surface. Taking into account the short time (3 months) of experiment and laboratory conditions, one can state that steel corroded more that would be expected for $\mathrm{Ca}(\mathrm{OH})_{2}$ rich environment. This behavior indicates, that in lime mortar is likely higher potential than in concrete; moreover in lime are not any alkalis like in cement which are responsible for higher $\mathrm{pH}$ than that corresponding to portlandite [6]. The zinc coated carbon steel was also subject of investigation, but one did not observed any corrosion effects.

Copper. The surface of copper (Fig. 3) has been covered by well adhering layer of mortar; one observes that mortar is more compact in the vicinity of copper sheet. A closer view (Fig. 4 indicates that the more compact surface layer is not homogenous; there are two phases. Both of them are dominated by $\mathrm{CaCO}_{3}$, as results from $\mathrm{Ca}$ and $\mathrm{C}$ profiles, but the phase in vicinity of copper plate is enriched by sulfur; its concentration is equal across the layer. The second element enriched in this layer is copper; its content is decreasing gradually in the layer and drops to zero on the interface between the two phases. The only source of sulfur in the system is lime, containing $0.1 \%$ of $\mathrm{SO}_{3}$. Due to low content, XRD diffraction was not able to detect, whether the is a sulfide or a sulfate salt.

Generally copper is immune in basic environment, or eventually, at higher potential, passivated by $\mathrm{Cu}_{2} \mathrm{O}$ or $\mathrm{CuO}$. In the studied system, copper surface is not seemingly corroded. On the other hand, certain amount of copper dissolved and formed a $\mathrm{Cu}-\mathrm{S}$ compound accumulating at the interface between copper and lime mortar. There has to be a driving force for diffusion of sulfur from bulk of lime to the interface; this driving force is a difference between sulfur activity 

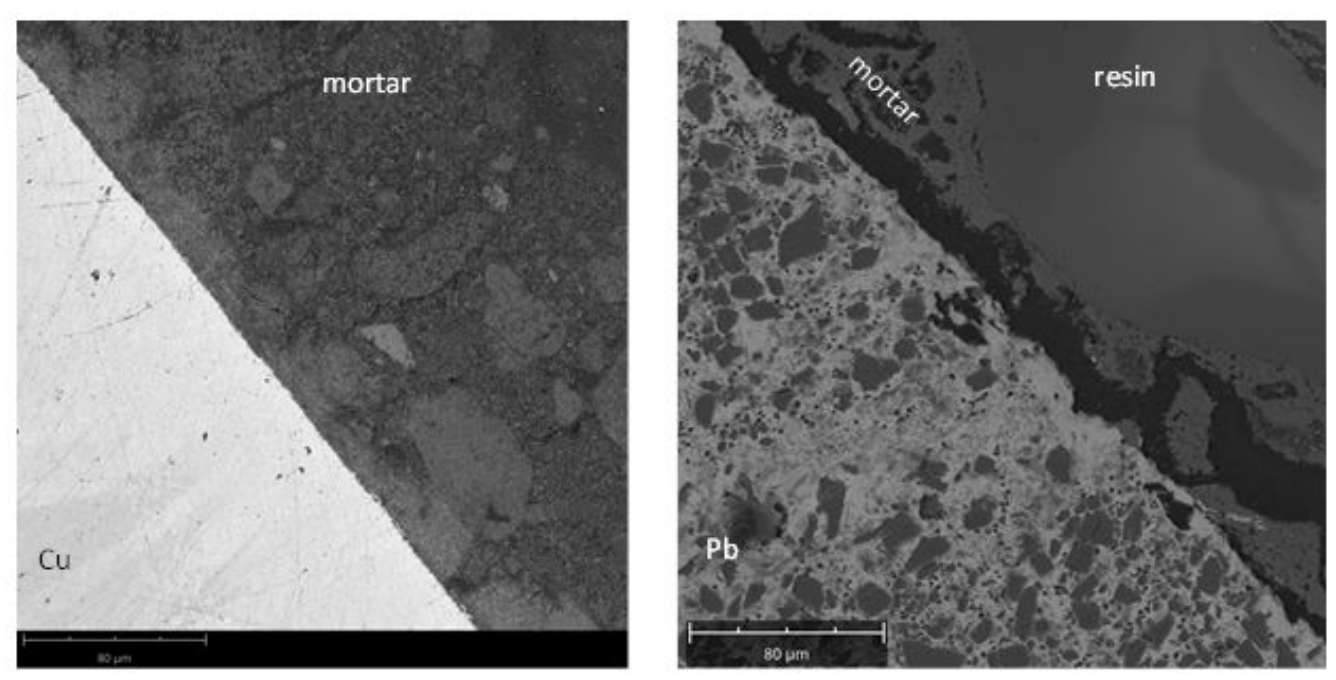

Figure 3. Interface of copper (left) and lead (right) with lime mortar.
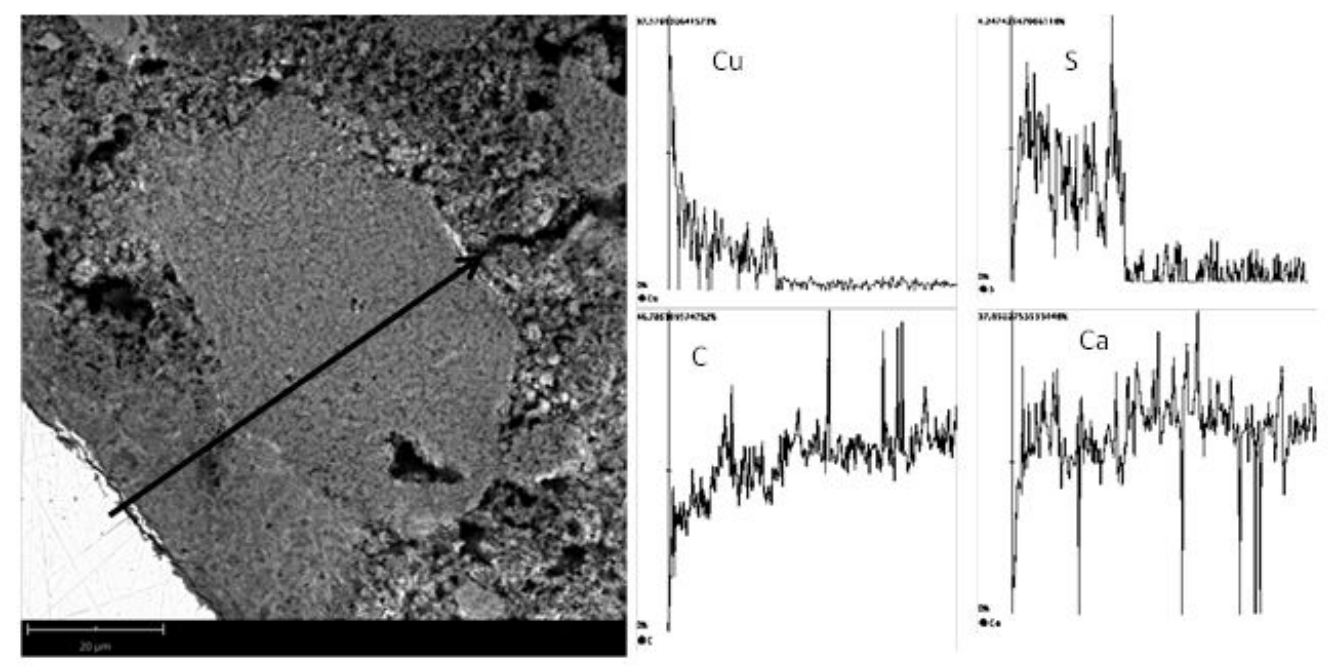

Figure 4. Detail of copper - lime interface. The arrow indicate line scan.
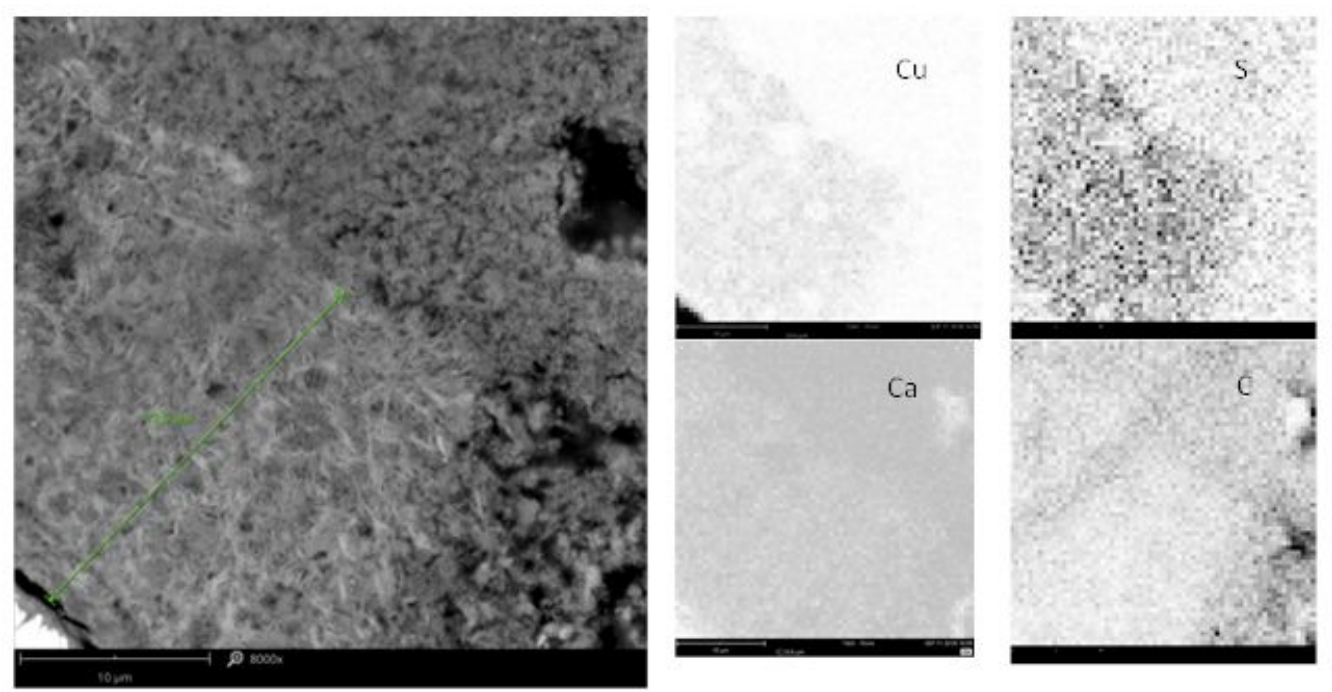

FIGURE 5. Elementary mapping performed on the copper - lime interface. 


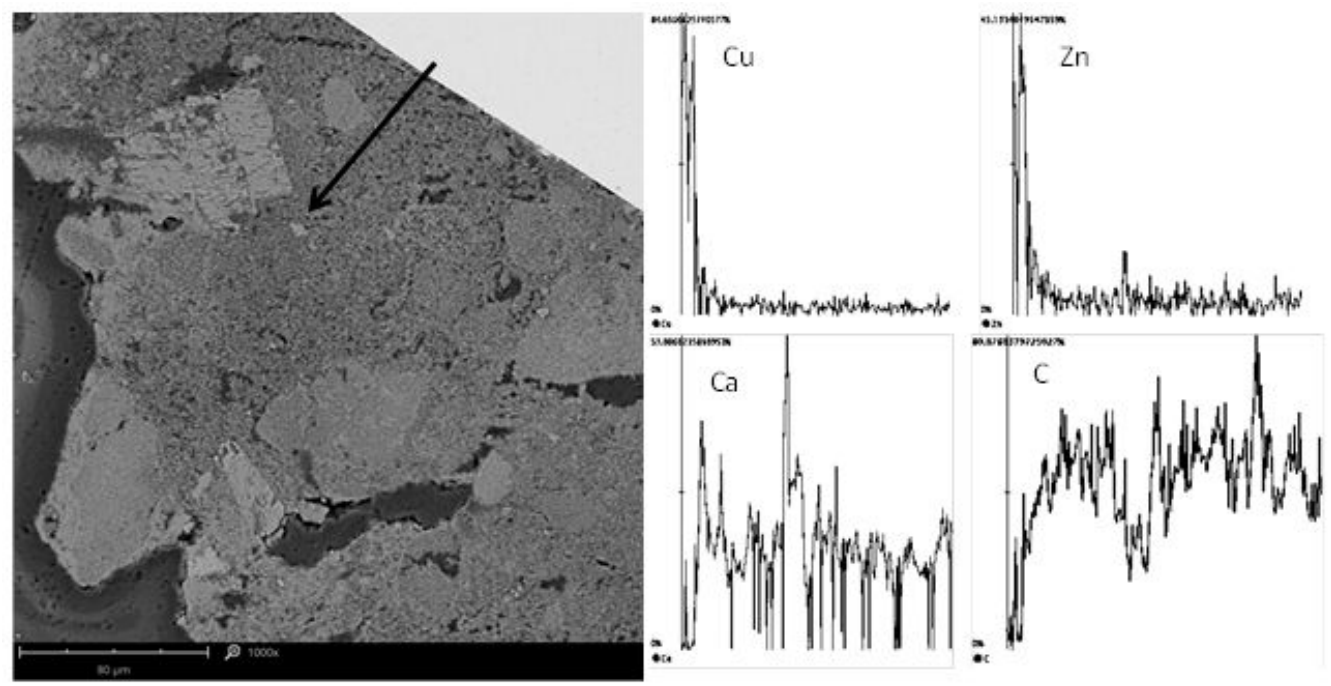

FIGURE 6. SEM micrograph of brass - lime interface. The arrow indicate line scan.
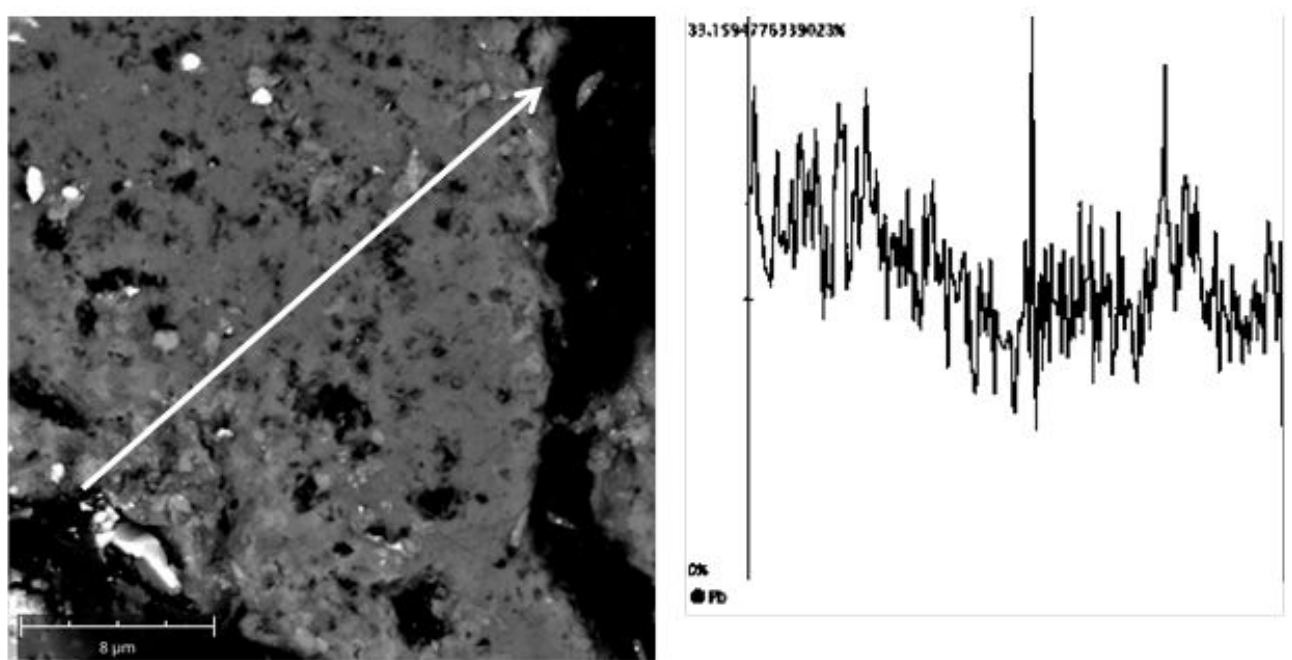

FiguRE 7. SEM micrograph of lime mortar on lead substrate. The arrow indicate $\mathrm{Pb}$ line scan.

in bulk and at the interface. It indicates that a $\mathrm{Cu}-\mathrm{S}$ compound precipitated in the adjacent layer, what lowered the interface activity of a dissolved S-species, consequently inducing the $\mathrm{S}$ transport to the copper vicinity. This process can be observed also by elementary mapping of the adjacent $\mathrm{Cu}-\mathrm{S}$ enriched layer (Fig. 5).

Brass. The interface between brass and lime mortar did not evince any indication of ongoing corrosion process (Fig. 6). Neither the element profiles did not indicate transfer of $\mathrm{Cu}$ or $\mathrm{Zn}$ from metal to the mortar phase. The mortar adhered well to the substrate. The results indicate that in the lime environment, zinc provides a passive layer to the brass and prevent its oxidation [7], even though in brass alloys, $\mathrm{Zn}$ is usually corroding preferentially to copper due to its lower standard electrochemical potential [8].

Lead. The adherence of lime mortar to lead was very poor (Fig. 3). The distinct crystals in lead are $\mathrm{SiC}$ particles, introduced, due to low hardness of lead, during the sample preparation. According to the lead Pourbaix diagram, it dissolves at $\mathrm{pH}$ above 11.5 to $\mathrm{Pb}(\mathrm{OH})_{4}^{2-}$ anion 9]; correspondingly the lead gradient was detected in the mortar (Fig. 7) where the formation of $\mathrm{CaPb}(\mathrm{OH})_{4}$ may be expected.

\section{Conclusions}

There is just a little attention paid, compared to concrete, to corrosion behavior of metals in contact with lime mortar. This environment is obviously also basic and its $\mathrm{pH}$ decreases in time, but the obtained results indicate important differences in behavior of these systems. Carbon steel, which is passive in concrete, corroded in lime mortar already after 3 months; the corroded layer developed between metal and adhering mortar. The zinc coated steel did not corroded in lime environment within the studied time range. Copper formed a $\mathrm{Cu}-\mathrm{S}$ corrosion product, dispersed in adjacent layer of mortar, despite it is relatively noble metal. On the other hand, zinc in brass provided 
passivation to the material and any corrosion has not been observed. The lead corroded to $\mathrm{Pb}(\mathrm{OH})_{4}^{2-}$ anion dispersed in lime mortar. It can be concluded that the best corrosion compatibility with the lime mortar environment proved brass and zinc coated steel.

\section{ACKNOWLEDGEMENTS}

The work has been supported by Czech Science Foundation project Nr. 18-13525S "Modern mosaic mortars in a microscope - methods for their materials characterization and degradation studies".

\section{REFERENCES}

[1] A. Poursaee (ed.). Corrosion of Steel in Concrete Structures. Elsevier Ltd., 2016. DOI:10.1016/C2014-0-01384-6

[2] A. Behnood, K. Van Tittelboom, N. De Belie. Methods for measuring $\mathrm{pH}$ in concrete: A review. Construction and Building Materials 105:176-188, 2016. DOI:10.1016/j.conbuildmat.2015.12.032.

[3] J. Němeček, T. Koudelka, T. Krejci. Numerical modeling of accelerated chloride transport in concrete. vol. 1978. 2018. DOI:10.1063/1.5043737
[4] I. Perná, T. Hanzlíček, M. Kracík Štorkánová. Characterization of historic mosaic at Pfeiffer-Kral Sepulcher, Jablonec Nad Nisou: A study of the mortar and tesserae origin. Ceramics Silikaty 58:308-313, 2014.

[5] Y. Ma, Z. Guo, L. Wang, J. Zhang. Experimental investigation of corrosion effect on bond behavior between reinforcing bar and concrete. Construction and Building Materials 152:240-249, 2017. DOI:10.1016/j.conbuildmat.2017.06.169.

[6] A. Poursaee. Corrosion of steel bars in saturated $\mathrm{Ca}(\mathrm{OH})_{2}$ and concrete pore solution. Concrete Research Letters 1(3):90-97, 2010.

[7] S. Thomas, N. Birbilis, M. Venkatraman, I. Cole. Corrosion of zinc as a function of pH. Corrosion 68:1-9, 2012. DOI: $10.5006 / 1.3676630$

[8] S. Selvaraj, S. Ponmariappan, M. Natesan,

N. Palaniswamy. Dezincification of brass and its control - An overview. Corrosion Reviews 21:41-74, 2003. DOI:10.1515/CORRREV.2003.21.1.41

[9] Y. Xie. Dissolution, Formation, and Transformation of the Lead Corrosion Product $\mathrm{PbO}_{2}$ : Rates and Mechanisms of Reactions that Control Lead Release in Drinking Water Distribution Systems. Ph.D. thesis, Washingthon University in St. Louis, 2010. 